\title{
Natural History of Back Pain in Older Adults over
} Five Years

\author{
Wendelien H. van der Gaag, MD, Wendy T. M. Enthoven, MD, PhD, \\ Pim A.J. Luijsterburg, PhD, Jantine van Rijckevorsel-Scheele, PhD, \\ Sita M.A. Bierma-Zeinstra, PhD, Arthur M. Bohnen, MD, PhD, \\ Maurits W. van Tulder, PhD, and Bart W. Koes, PhD
}

Introduction: Back pain is a prevalent health problem. Research often focuses on adults. Evidence on the long-term course of back pain in older patients is limited. A prospective cohort study (BACE) was conducted in a primary care setting in the Netherlands. We aim to investigate the 5 -year course and medical consumption of older adults ( $>55$ years) presenting with back pain in general practice.

Methods: Patients aged > 55 years, consulting their general practitioner with a new back pain episode, were included between 2009 to 2011 . Follow-up questionnaires included, for example, pain severity, disability, quality of life, recovery, and medical consumption.

Results: A total of 675 patients (mean age \pm SD, $66.4 \pm 7.6$ years) participated, showing a mean ( \pm SD) back pain reduction from $5.2( \pm 2.7)$ to $3.6( \pm 2.8)$ (numeric rating scale, 0 to 10) at 3 months follow-up; disability decreased from $9.8( \pm 5.8)$ to $7.8( \pm 6.2)$ (Roland-Morris Disability Questionnaire, 0 to 24). After 6 months, this remained practically constant over time. Medical consumption was highest in the first months; medication was used by $72 \%$ at baseline and approximately onethird (25\% to 39\%) during follow-up. At 5-year follow-up (response rate 58\%; $n=392$ ), $43 \%$ had recovered; a majority reported persistent or recurrent back pain.

Conclusion: Clinically relevant improvements in back pain intensity and disability were seen in the first 3 to 6 months of follow-up. A majority of patients does not become pain free within 3 months; this does not improve over 5 years. However, most patients stop consulting health care professionals during follow-up. Current medical strategies may not be sufficient in older back pain patients, where back pain becomes a recurrent or chronic condition in the majority of patients. (J Am Board Fam Med 2019;32: 781-789.)

Keywords: Analgesics, Back Pain, Follow-Up Studies, General Practitioners, Netherlands, Primary Health Care, Prospective Studies, Quality of Life, Surveys and Questionnaires

Back pain is still one of the leading causes of years lived with disability. ${ }^{1}$ Recent publications of a Lancet Series on low back pain show once more that it

This article was externally peer reviewed.

Submitted 30 January 2019; revised 26 June 2019; accepted 28 June 2019.

From Department of General Practice, Erasmus MC, University Medical Center, Rotterdam, The Netherlands (WHvdG, WTME, PAJL, SMAB-Z, AMB, BWK); Research Centre Innovations in Care, Rotterdam University of Applied Sciences, Rotterdam, The Netherlands (JvR-S); Department of Orthopedics, Erasmus MC, University Medical Center, Rotterdam, the Netherlands (SMAB-Z); Department of Health Sciences \& Amsterdam Movement Sciences Institute, Faculty of Science, Vrije Universiteit Amsterdam, The Netherlands (MWvT); Department of Physiotherapy is a prevalent health problem that needs our ongoing attention. ${ }^{2-4}$ It can cause serious limitations in work and daily life activities, and the socioeco-

\& Occupational Therapy, Aarhus University Hospital, Aarhus, Denmark (MWvT); Center for Muscle and Health, University of Southern Denmark, Odense, Denmark (BWK)

Funding: This study was funded by the Department of General Practice, Erasmus University Medical Center, Rotterdam, and the Coolsingel Foundation, Rotterdam and partly funded by a program grant of the Dutch Arthritis Foundation; all are based in the Netherlands.

Conflict of interest: none declared.

Corresponding author: Wendelien H. van der Gaag, MD, Department of General Practice, Erasmus MC, PO Box 2040, 3000 CA Rotterdam, the Netherlands (E-mail: w.vandergaag@erasmusmc.nl). 
nomic burden is high. ${ }^{5}$ A considerable amount of patients nearly or completely recover from their back pain within the first 6 weeks. Despite this, the numbers of recurrent and chronic symptoms reported after 1 year are substantial. ${ }^{6-8}$ There is a tendency in clinical guidelines across countries to urge for a more conservative approach concerning the prescription of analgesics. They recommend limiting analgesic usage to shorter time periods, considering the risk of adverse drug reactions. Recent guidelines encourage proactive treatment, focusing on reassurance, patient education, advice to return to normal activities, and taking psychosocial factors into account. ${ }^{9}$

Research on back pain was often limited to the working population. However, the ageing population especially in industrialized countries brings new challenges and considerations. Little is known about the long-term course of back pain in older adults. A 2012 systematic review indicated that not all patients with persisting back pain return to their general practitioner (GP). ${ }^{10}$ This cohort study was started to determine the clinical course (duration and severity) and medical consumption of back pain in older people visiting their GP with a new episode of back pain. ${ }^{11}$ In this article, we report the 5 -year clinical course and medical consumption of this cohort.

\section{Methods}

\section{Study Design and Setting}

The study "Back Complaints in the Elders" (BACE) is a prospective cohort study and part of the BACE consortium. In the Netherlands, 675 patients aged $>55$ years were included between March 2009 and September 2011, consulting their GP with a new episode of back pain. An episode was defined as "new" if the patient had not consulted a GP for the same symptoms in the preceding 6 months. Back pain was defined as pain in the region from the top of the shoulder blades to the first sacral vertebra. Patients with a language barrier or cognitive disorder were excluded, as were patients who were unable to undergo the physical examination (e.g., wheelchair-bound patients). For the detailed study design, we refer to the previously published study protocol, approved by the local medical ethics committee. ${ }^{11}$

\section{Data Collection}

Data were collected using self-report questionnaires, with follow-up measurements at 3,6, and 9 months and 1, 2, 3, 4, and 5 years, and through physical examination. Back $\mathrm{x}$-rays from all patients were obtained at baseline. Baseline measurements included the following:

(1) Patient characteristics. General characteristics were collected such as age, sex, education level, smoking, and patients' expectation of recovery; quality of life was measured with the physical and mental summary scale of the Short Form-36 (SF$36)^{12}$; depressive symptomatology was measured with the Center for Epidemiologic Studies Depression $\mathrm{Scale}^{13}$; kinesiophobia was measured with the physical activity subscale of the Fear-Avoidance Beliefs Questionnaire ${ }^{14}$; pain catastrophizing was measured with the Pain Catastrophizing Scale ${ }^{15}$; and musculoskeletal comorbidity (neck, shoulder, knee, or hip symptoms) was partially measured with the Self-Administered Comorbidity Questionnaire $^{16}$ and complemented with some additional questions during physical examination.

(2) Characteristics of the back pain at baseline. Duration of symptoms; back pain severity measured with an 11-point Numeric Rating Scale (NRS), ranging from 0 ("no pain") to 10 ("worst pain ever") ${ }^{17}$; disability measured with the RolandMorris Disability Questionnaire (RMDQ), ranging from 0 ("no disabilities") to 24 points ("maximal disability") ${ }^{18}$; history of back pain; the presence of radiating pain in the leg below the knee; and perceived cause of the back pain.

Follow-up questionnaires included the following:

(1) Clinical course. Self-perceived recovery, measured with the Global Perceived Effect (GPE) scale, a 7-point scale ranging from 1 ("completely recovered") to 7 ("worse than ever") ${ }^{19}$; average severity of back pain during last week (NRS); disability (RMDQ); and quality of life (SF-36).

(2) Medical consumption. Self-reported medication use for back pain-both over-the-counter and on prescription - in the time periods between questionnaires (dichotomous yes/no, at time points 3, 6, and 9 months and 1 to 5 years), and, if so, which medication (maximum 3 answers); self-reported nonpharmacological treatments, such as visits to health care professionals (e.g., GP, physiotherapist, and medical specialist); ordered diagnostic tests (e.g., blood tests, x-rays, and magnetic resonance 
imaging or computed tomography scan); and surgery, if so, for which indication.

\section{Data Analysis}

Descriptive analyses were used to describe patient characteristics and report the clinical course of back pain over a 5-year period. Recovery was defined as a self-perceived recovery score of 1 to 2 on the 7-point GPE scale ("completely recovered" or "strongly improved") at a specific time point; a score of 3 to 7 was defined as nonrecovery, which could represent either persistent or recurrent pain. All patient-reported medications were recorded and split into 7 categories: (1) paracetamol, (2) nonsteroidal anti-inflammatory drug (NSAID), (3) opioid, (4) muscle relaxant, (5) antidepressant, (6) anticonvulsant, and (7) other medication. Data were analyzed using SPSS version 24.0.

\section{Results}

\section{Population Characteristics}

Figure 1 shows the process of patient inclusion and follow-up. A total of 1,402 patients were invited to participate in the BACE study, of which 675 patients were included. Potential participants were recruited either directly during consultation or in writing after consultation. Response rates gradually decreased from $99 \%(\mathrm{n}=670)$ at baseline, to $93 \%$ $(\mathrm{n}=626)$ at 3 months follow-up, $88 \%(\mathrm{n}=591)$ at 1 year, and $58 \%(\mathrm{n}=392)$ after 5 years. Some patients moved $(2 \%)$ or passed away $(3 \%)$ during follow-up; others refrained from participation in the follow-up questionnaires or did not respond. Baseline characteristics of all included patients are shown in Table 1 . The mean $( \pm \mathrm{SD})$ age was 66.4 years ( \pm 7.6 ; range 56 to 91 years), $41 \%$ were male. The mean average $( \pm \mathrm{SD})$ back pain in the previous week was $5.2( \pm 2.7$; NRS 0 to 11$)$, whereas mean disability $( \pm \mathrm{SD})$ at baseline was $9.8( \pm 5.8$; RMDQ 0 to 24). Most patients had previous episodes of back pain $(86 \%, \mathrm{n}=579)$ and reported musculoskeletal comorbidity (77\%, $\mathrm{n}=519)$; a minority reported back surgery in the past $(8 \%, \mathrm{n}=56)$.

\section{Clinical Course of Back Pain}

Table 2 and Figure 2 show the clinical course of back pain in this elderly cohort. Over the course of 5 years, clinically relevant improvements in both average back pain severity and average disability scores were mainly seen in the first 3 months of follow-up, with a mean pain reduction from 5.2 $( \pm 2.7)$ to $3.6( \pm 2.8)$ on the 11-point NRS scale, and a reduction in disability from $9.8( \pm 5.8)$ to 7.8 $( \pm 6.2)$ on the 24-point RMDQ-scale. Hereafter,

\section{Figure 1. Flowchart of the initial patient recruitment process.}

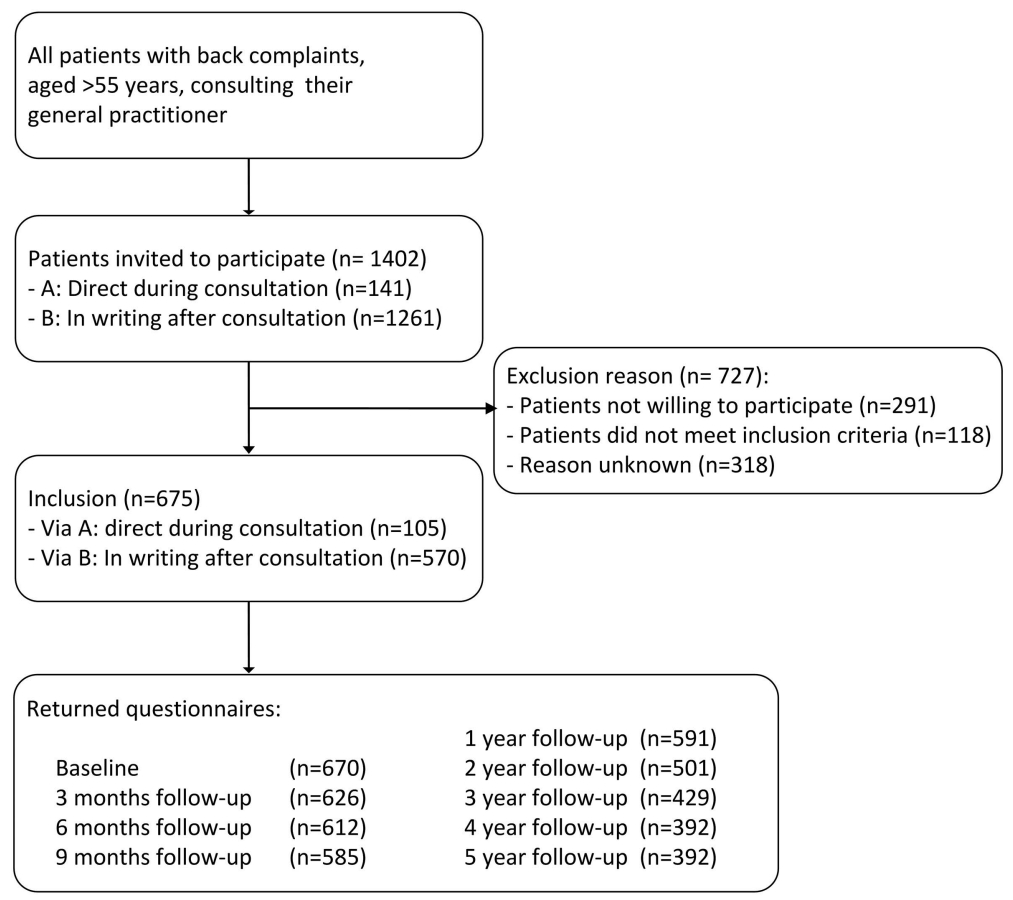


Table 1. Baseline Characteristics*

\begin{tabular}{|c|c|}
\hline Characteristics & $\begin{array}{l}\text { All values, } \\
\mathrm{n}=675\end{array}$ \\
\hline \multicolumn{2}{|l|}{ General } \\
\hline Age in years, mean $\pm \mathrm{SD}$ & $66.4 \pm 7.6$ \\
\hline Male, n (\%) & $274(41)$ \\
\hline $\mathrm{BMI}$, mean $\pm \mathrm{SD}$ & $27.5 \pm 4.7$ \\
\hline$<$ Low education level, n (\%) & $279(41)$ \\
\hline Smoking, n (\%) & $122(18)$ \\
\hline \multicolumn{2}{|l|}{ Back pain } \\
\hline \multicolumn{2}{|l|}{ Duration of back pain, $\mathrm{n}(\%)$} \\
\hline$<1$ week & $62(9)$ \\
\hline 1 week- 6 weeks & $273(40)$ \\
\hline 6 weeks -3 months & $104(15)$ \\
\hline$>3$ months & $156(23)$ \\
\hline $\begin{array}{l}\text { Average back pain previous week (NRS), } \\
\text { mean } \pm \text { SD }\end{array}$ & $5.2 \pm 2.7$ \\
\hline $\begin{array}{l}\text { Radiating pain in the leg below the knee, } \\
\mathrm{n}(\%)\end{array}$ & $205(30)$ \\
\hline Disability (RMDQ), mean \pm SD & $9.8 \pm 5.8$ \\
\hline History of back pain, $\mathrm{n}(\%)$ & $579(86)$ \\
\hline Back surgery in the past, $\mathrm{n}(\%)$ & $56(8)$ \\
\hline $\begin{array}{l}\text { Comorbidity musculoskeletal complaints, } \\
\mathrm{n}(\%)\end{array}$ & $519(77)$ \\
\hline \multicolumn{2}{|l|}{ Medical consumption } \\
\hline Use of pain medication for back pain, $\mathrm{n}(\%)$ & $485(72)$ \\
\hline Care from a physical therapist, $\mathrm{n}(\%)$ & $299(44)$ \\
\hline \multicolumn{2}{|l|}{ Psychological factors } \\
\hline $\begin{array}{l}\text { Patients' expectation to recover of back pain, } \\
\text { n (\%) }\end{array}$ & $291(43)$ \\
\hline $\begin{array}{l}\text { Quality of life (SF-36) physical summary } \\
\text { scale, mean } \pm \text { SD }\end{array}$ & $43.2 \pm 8.9$ \\
\hline $\begin{array}{l}\text { Quality of life (SF-36) mental summary scale, } \\
\text { mean } \pm \mathrm{SD}\end{array}$ & $49.6 \pm 10.3$ \\
\hline $\begin{array}{l}\text { Depressive symptomatology (CES-D), } \\
\text { mean } \pm \mathrm{SD}\end{array}$ & $10.0 \pm 7.8$ \\
\hline $\begin{array}{l}\text { Kinesiophobia (FABQ), physical activity } \\
\text { subscale, mean } \pm \text { SD }\end{array}$ & $13.4 \pm 5.8$ \\
\hline Pain catastrophizing $(\mathrm{PCS})$, mean $\pm \mathrm{SD}$ & $14.1 \pm 10.6$ \\
\hline $\begin{array}{l}\text { Attitude and beliefs about back pain (BBQ), } \\
\text { mean } \pm \text { SD }\end{array}$ & $26.4 \pm 7.2$ \\
\hline
\end{tabular}

*BMI, body mass index $\left(\mathrm{kg} / \mathrm{m}^{2}\right)$; CI, confidence interval; NRS, numeric rating scale (range, 0 to 10 ); RMDQ, Roland Morris disability questionnaire (range, 0 to 24); SF-36, Short Form-36; physical and mental summary scale (range, 0 to 100); CES-D, Center for Epidemiologic Studies Depression Scale (range, 0 to 60); FABQ, Fear-avoidance beliefs questionnaire, physical subscale (range, 0 to 28); PCS, Pain Catastrophizing Scale (range, 0 to 52); BBQ, Back beliefs questionnaire (range, 9 to 45 ).

the reported average back pain and disability stabilized, with a mean back pain severity of $3.4( \pm 2.8)$ and mean disability of $7.2( \pm 6.1)$ after 6 months, and remained practically constant over the following years, for example, with scores of $3.0( \pm 2.9)$ and $6.7( \pm 6.2)$, respectively, after 5 years. The mean perceived quality of life on both the physical and mental health level (SF-36 subscales, score range 0 to 100$)$ edged around 50 over the complete 5 -year course.

Recovery is shown in Table 2. At 3 months, $38 \%$ had nearly or completely recovered from their back pain; at 5 years follow-up, this value was $43 \%$. More than half of the patients did not recover and reported persistent or recurrent back pain 5 years after their symptoms started.

\section{Medical Consumption}

Table 2 and Figure 3 show patients' self-reported information on medical consumption. We distinguished consulting health care professionals, additional examinations that were performed, medication usage, and surgery; all related to the back complaints. At 3 months follow-up, approximately a quarter $(26 \%)$ have revisited their GP for their back pain. Thereafter, $8 \%$ to $14 \%$ of the patients seek GP consultation for their persistent or recurrent back pain. The decline in care from a physical therapist is slower but similar to the GP visits. Consultation of medical specialists remains constant, with a range of $6 \%$ to $11 \%$ of the patients visiting a medical specialist in the previous months/ year, respectively. For diagnostic reasons, 29\% were referred for radiograph in the first 3 months. Referral for blood tests (13\%) or magnetic resonance imaging $(7 \%)$ was less common.

A total of $72 \%$ of the total population reported using a form of medication for their back pain at baseline, both over-the-counter and on prescription. Thereafter, the average amount of patients taking medication remained quite constant (range, $25 \%$ to $39 \%$ of the total population). Paracetamol and NSAIDs were the most frequently reported medications at baseline (by $49 \%$ and $57 \%$ of all medication users, respectively), followed by opioids $(17 \%)$, and muscle relaxants/sleep medication (8\%). Over the course of 5 years, these numbers remained constant, with $57 \%$ to $62 \%$ reporting paracetamol usage among the patients using medication and $37 \%$ to $45 \%$ reporting using NSAIDs. The percentage of opioid users among the medication users raised from $16 \%$ to $17 \%$ in the first year, to $22 \%$ to $28 \%$ in the following years. Eighteen patients reported surgery during follow-up, of whom 13 had persistent complaints due to spinal stenosis; in other cases, the reason for surgery remained unknown. Five of these 18 patients had a 


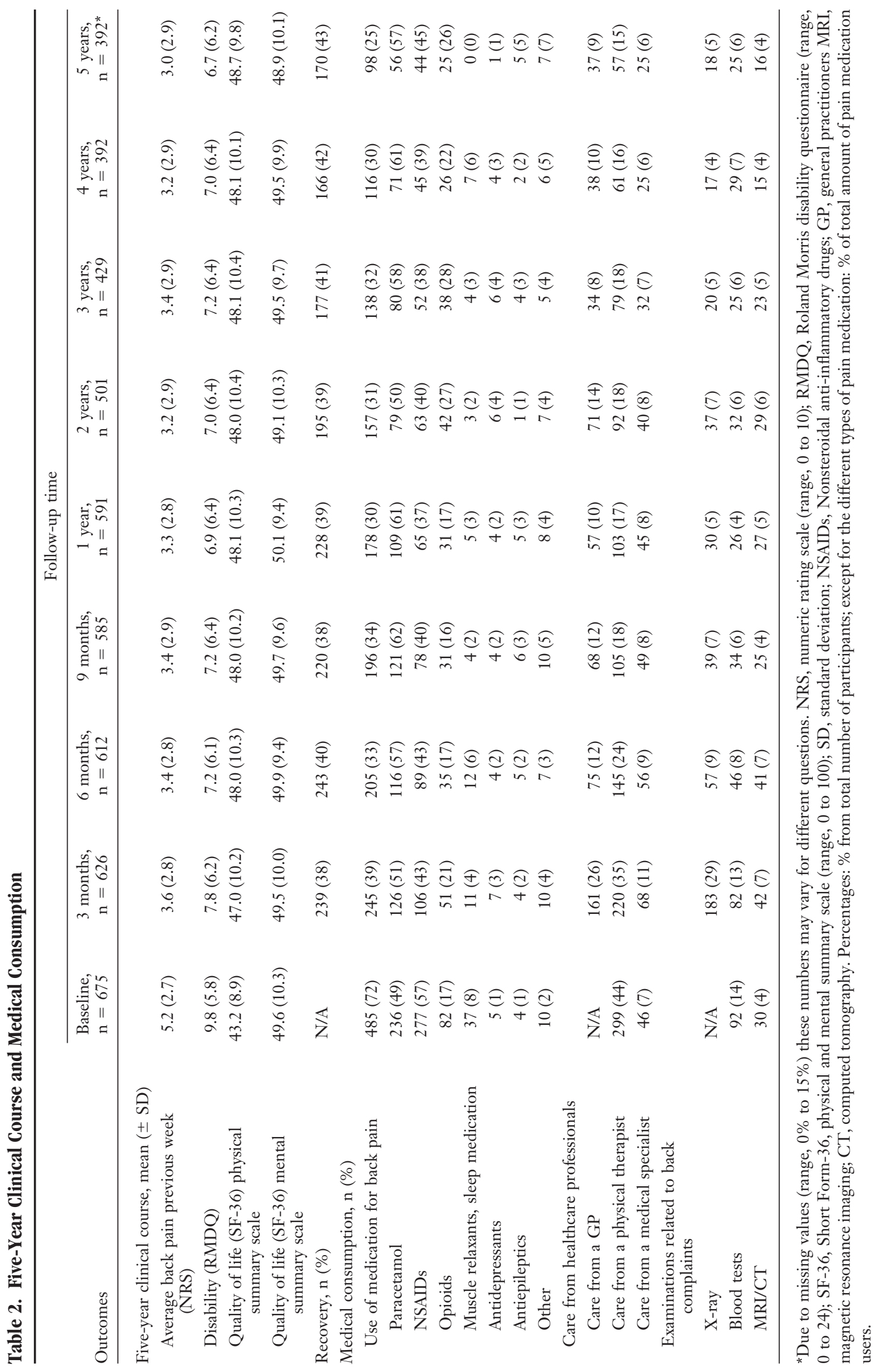


Figure 2. Clinical course. A: Average back pain in the previous week, mean \pm SD; NRS, numeric rating scale (range 0 to 10). B: Disability in the previous week, mean \pm SD; RMDQ, Roland Morris disability questionnaire (range 0 to 24). C: Quality of life on the physical (blue) and mental (red) summary scales, mean \pm SD; SF-36, Short Form-36, physical and mental summary scale (range 0 to 100).
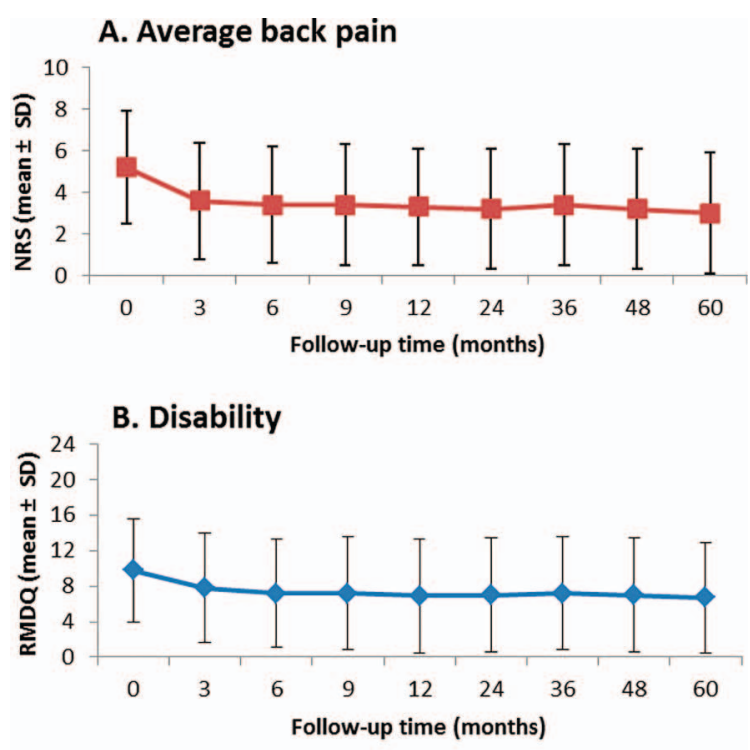

\section{Quality of life (physical \& mental level)}

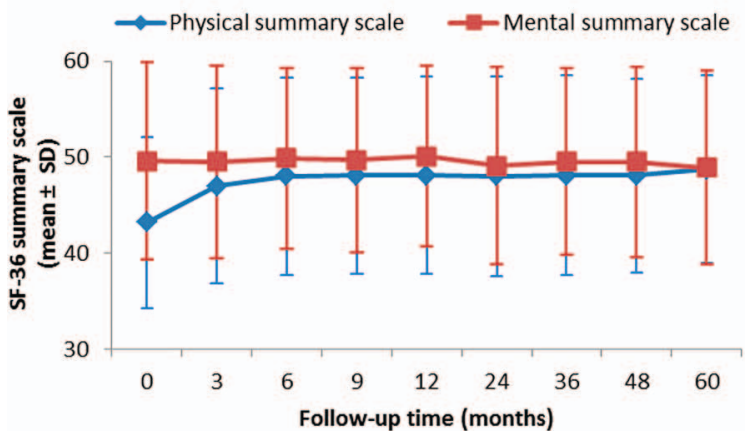

history of back surgery at baseline. In general, either a laminectomy or spinal fusion was performed. Three patients reported multiple back surgeries during follow-up.

\section{Discussion}

\section{Summary}

This article presents the average 5-year clinical course of back pain in older patients visiting their GP with a new episode of back pain. This is the first time a cohort of elderly patients was followed for a
Figure 3. Medical consumption. A: Self-reported use of medication (\% patients using this type of medication from all patients using medication). B: Self-reported consultations of health care professionals (\% of total response). C: Self-reported diagnostic referrals (\% of total response).
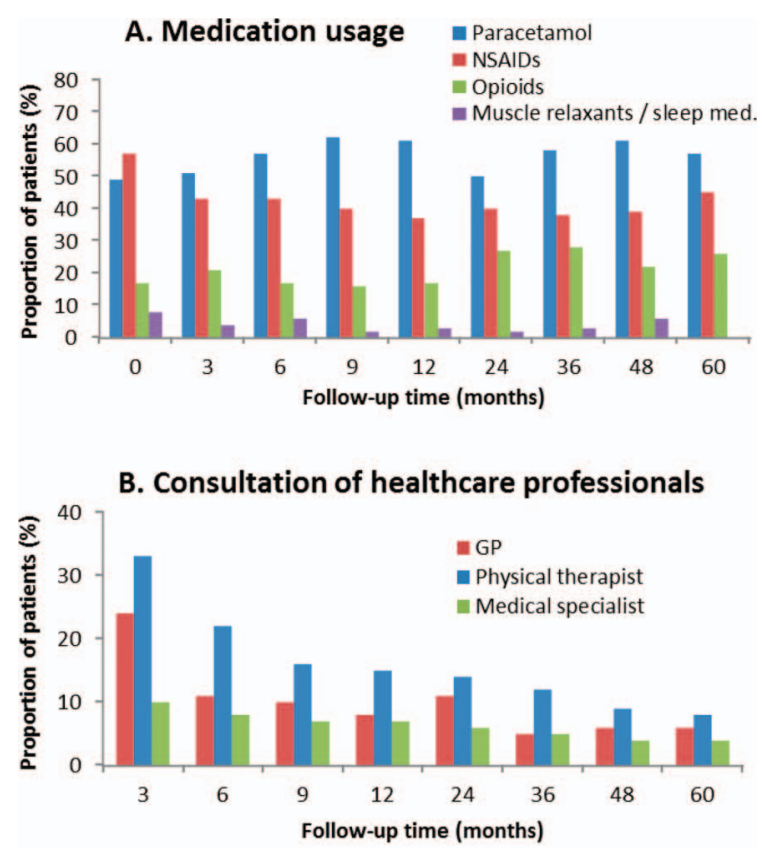

\section{Diagnostic referrals}

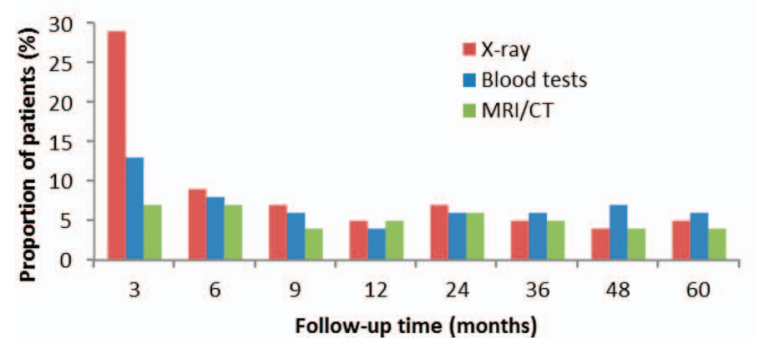

longer period of time, which gives new insights on the course of back pain in the elderly over time. At 5 -year follow-up, $43 \%$ reported themselves as (almost) completely recovered. The average clinical outcomes over the 5 -year course show that main improvements in both pain, disability, and physical quality of life occur in the first 3 months of followup. After these 3 months, the average levels of pain and disability remain practically constant over time. In other words, a majority of patients experience persistent or recurrent back pain.

Medical consumption, mainly pain medication, remains substantial, with approximately one-third of the cohort (range $25 \%$ to $39 \%$ ) using at least 1 type of medicine for their back pain. However, over 
time, patients report less contact with health care professionals. This implies most patients do not consult their GP or other medical health care professionals after the first year, despite having persistent (or recurrent) back pain. They are "out of sight," but their problem may not be solved. Either they have accepted their disability and pain level and learned strategies on how to cope with their back pain, or patients refrain from a visit because they assume it will not help them further in alleviating the pain. It remains unknown if patients seek help from other health care workers or find alternative options to relieve their pain; this was not included in our follow-up questionnaires. For future research, we would suggest qualitative research to determine this.

\section{Strengths and Limitations}

This is the first cohort of elderly with back pain with a long-term follow-up. Previous studies concerning back pain in older adults had a maximum of 1 year follow-up. ${ }^{20,21}$ The 5 -year follow-up showed that back pain in older patients follows a similar pattern in terms of pain relief and (initial) recovery in the first months; but over time, more than half of the patients still experience (persistent or recurrent) mild to moderate back pain.

The longitudinal nature of the study is a strength but also a limitation. It was not possible to distinguish between persistent or recurrent symptoms. Patients could be "recovered" at 1 time point and not recovered at another. Since most patients had a history of back pain, it is probable that many had recurrences and did not recover persistently.

Longer follow-up often leads to lower response rates, which we tried to prevent by adding the option of phone interviews as a follow-up measure. However missing data are still inevitable. It is possible that patients who did not fill out the follow-up questionnaires had less persistent back symptoms and/or experienced less disability than patients who participated until the final year of follow-up. A potential selection bias that could lead to an overrepresentation of relatively worse outcomes. The $29 \%$ of patients that reported referral for radiograph in the first 3 months after the baseline measurements is probably not reflecting usual care. Because back x-rays of all patients were obtained at baseline for research purposes, this is probably an overestimation.
We aimed to show a broad picture of the average clinical course of back pain in older adults. Most outcome measures showed a wide variation, suggesting different subgroups of patients who experience either less or more disability and pain or a fluctuating individual course of back pain. These different trajectories of back pain in this cohort were previously described by Enthoven et al. ${ }^{22}$, and common trajectories for back pain in adults in general have been described by several researchers. $^{23-27}$ For the management of individual patients, it would be useful to be able to estimate the risk of chronic back pain in an early stage and tailor the treatment toward their needs.

\section{Comparison with Existing Literature}

Previous studies have reported on the course and prognosis of adults with recent-onset low back pain. ${ }^{6-8,10,28,29}$ Most of these findings are consistent with our results, marking a clinically relevant pain and disability reduction in the first 6 weeks, up to 3 months, with only small reductions thereafter. Hestbaek et al. ${ }^{28}$ reported that $62 \%$ (range, $42 \%$ to $75 \%$ ) of the subjects experience persistent back pain after 1 year, and Itz et al. $^{8}$ reported $65 \%$ (range, $57 \%$ to $71 \%$ ), which are consistent with our results. Other authors report slightly lower numbers of persistent pain. In a review from Scheele et al. ${ }^{10}$ on the course of back pain in adults above 45 years, persistent back pain ranged from $26 \%$ to $45 \%$ at 12 months follow-up. Henschke et al. ${ }^{29}$ mentioned nearly one-third of their cohort (aged $>14$ years; mean age 43.3) had not recovered from the initial episode of back pain after 1 year. One of the variables independently associated with a poor prognosis was older age. This could be one of the reasons the numbers of nonrecovery in our cohort were higher. Furthermore, the majority of patients have had previous episodes of back pain, which is also identified as a prognostic factor for nonrecovery. ${ }^{30}$ A review from Dionne et al. ${ }^{31}$ suggests that especially the frequency of severe back pain increases with increasing age. Rundell et al. ${ }^{21}$ presented the results of their United States-based cohort with older adults. After 1 year of follow-up, they reported $60.3 \%$ of the patients with persistent disability and $50.7 \%$ with persistent back pain. ${ }^{21}$ This seems consistent with our results showing $61 \%$ nonrecovery after 1 year. 


\section{Conclusion}

This article described the average 5-year clinical course in a cohort of older patients with back pain. Most important findings are the following: (1) clinically relevant improvements in pain intensity, disability, and physical quality of life take place in the first 3 months of follow-up. After this initial period, the average mean pain intensity and disability remain constant over time. (2) Approximately onethird (range, $25 \%$ to $39 \%$ ) used medication at any time point during follow-up; mainly paracetamol, NSAIDs, and opioids. (3) After 5 years, more than half of the study population has not recovered from their back pain. However, most patients stop consulting their GP or physical therapist during follow-up. In conclusion, a substantial amount of older patients does not become fully pain free within 5 years follow-up. Current medical strategies for older back pain patients may need to be re-evaluated.

The authors thank all study participants, participating GPs, the project team, and research assistants.

To see this article online, please go to: http://jabfm.org/content/ 32/6/781.full.

\section{References}

1. Vos T, Abajobir AA, Abate KH, et al. Global, regional, and national incidence, prevalence, and years lived with disability for 328 diseases and injuries for 195 countries, 1990-2016: a systematic analysis for the Global Burden of Disease Study 2016. Lancet 2017;390:1211-1259.

2. Hartvigsen J, Hancock MJ, Kongsted A, et al. What low back pain is and why we need to pay attention. Lancet 2018;391:2356-67.

3. Foster NE, Anema JR, Cherkin D, et al. Prevention and treatment of low back pain: evidence, challenges, and promising directions. Lancet 2018;391:2368-83.

4. Buchbinder R, van Tulder M, Öberg B, et al. Low back pain: a call for action. Lancet 2018;391:2384-8.

5. Hoy D, March L, Brooks P, et al. Measuring the global burden of low back pain. Best Pract Res Clin Rheumatol 2010;24:155-65.

6. Pengel LHM, Herbert RD, Maher CG, et al. Acute low back pain: systematic review of its prognosis. BMJ 2003;327:323-323.

7. Menezes Costa LdC, Maher CG, Hancock MJ, et al. The prognosis of acute and persistent low-back pain: a meta-analysis. CMAJ 2012;184:E613-E624.

8. Itz CJ, Geurts JW, van Kleef M, et al. Clinical course of non-specific low back pain: a systematic review of prospective cohort studies set in primary care. Eur J Pain 2013;17:5-15.

9. Oliveira CB, Maher CG, Pinto RZ, et al. Clinical practice guidelines for the management of non-specific low back pain in primary care: an updated overview. Eur Spine J 2018;27:2791-2803.

10. Scheele J, Luijsterburg PA, Bierma-Zeinstra SM, et al. Course of back complaints in older adults: a systematic literature review. Eur J Phys Rehabil Med 2012;48:379-386.

11. Scheele J, Luijsterburg PAJ, Ferreira ML, et al. Back complaints in the elders (BACE); design of cohort studies in primary care: an international consortium. BMC Musculoskelet Disord 2011;12:1.

12. Ware JE, Jr., Gandek B. Overview of the SF-36 Health Survey and the International Quality of Life Assessment (IQOLA) Project. J Clin Epidemiol 1998;51:903-912.

13. Radloff LS. The CES-D scale: a self-report depression scale for research in the general population. Appl Psychol Meas 1977;1:385-401.

14. Waddell G, Newton M, Henderson I, et al. A FearAvoidance Beliefs Questionnaire (FABQ) and the role of fear-avoidance beliefs in chronic low back pain and disability. Pain 1993;52:157-168.

15. Sullivan MJL, Bishop SR. The pain catastrophizing scale: development and validation. Psychol Assess 1995;7:524-32.

16. Sangha O, Stucki G, Liang MH, et al. The SelfAdministered Comorbidity Questionnaire: a new method to assess comorbidity for clinical and health services research. Arthritis Rheum 2003;49:156-163.

17. Von Korff M, Jensen MP, Karoly P. Assessing global pain severity by self-report in clinical and health services research. Spine 2000;25:3140-3151.

18. Roland M, Morris R. A study of the natural history of back pain. Part I: development of a reliable and sensitive measure of disability in low-back pain. Spine 1983;8:141-144.

19. Beurskens AJ, de Vet HC, Koke AJ. Responsiveness of functional status in low back pain: a comparison of different instruments. Pain 1996;65:71-76.

20. Rundell Sean D, Sherman Karen J, Heagerty Patrick $\mathrm{J}$, et al. The clinical course of pain and function in older adults with a new primary care visit for back pain. J Am Geriatr Soc 2015;63:524-30.

21. Rundell SD, Sherman KJ, Heagerty PJ, et al. Predictors of persistent disability and back pain in older adults with a new episode of care for back pain. Pain Med 2017;18:1049-1062.

22. Enthoven WTM, Koes BW, Bierma-Zeinstra SMA, et al. Defining trajectories in older adults with back pain presenting in general practice. Age and Ageing. 2016;45:878-883.

23. Kongsted A, Kent P, Hestbaek L, et al. Patients with low back pain had distinct clinical course patterns that were typically neither complete recovery nor 
constant pain. A latent class analysis of longitudinal data. Spine J 2015;15:885-94.

24. Macedo LG, Maher CG, Latimer J, et al. Nature and determinants of the course of chronic low back pain over a 12-month period: a cluster analysis. Phys Ther 2014;94:210-221.

25. Downie AS, Hancock MJ, Rzewuska M, et al. Trajectories of acute low back pain: a latent class growth analysis. Pain 2016;157:225-34.

26. Dunn KM, Jordan K, Croft PR. Characterizing the course of low back pain: a latent class analysis. Am J Epidemiol 2006;163:754-761.

27. Axén I, Leboeuf-Yde C. Trajectories of low back pain. Best Prac Res Clin Rheumatol 2013;27: 601-12.
28. Hestbaek L, Leboeuf-Yde C, Manniche C. Low back pain: what is the long-term course? A review of studies of general patient populations. Eur Spine J 2003;12:149-165.

29. Henschke N, Maher CG, Refshauge KM, et al. Prognosis in patients with recent onset low back pain in Australian primary care: inception cohort study. BMJ 2008;337:a171.

30. Scheele J, Enthoven WT, Bierma-Zeinstra SM, et al. Course and prognosis of older back pain patients in general practice: a prospective cohort study. Pain 2013;154:951-7.

31. Dionne CE, Dunn KM, Croft PR. Does back pain prevalence really decrease with increasing age? A systematic review. Age and Ageing. 2006;35:229234. 